

\section{DISCLAIMER}

This report was prepared as an account of work sponsored by an agency of the United States Government. Neither the United States Government nor any agency Thereof, nor any of their employees, makes any warranty, express or implied, or assumes any legal liability or responsibility for the accuracy, completeness, or usefulness of any information, apparatus, product, or process disclosed, or represents that its use would not infringe privately owned rights. Reference herein to any specific commercial product, process, or service by trade name, trademark, manufacturer, or otherwise does not necessarily constitute or imply its endorsement, recommendation, or favoring by the United States Government or any agency thereof. The views and opinions of authors expressed herein do not necessarily state or reflect those of the United States Government or any agency thereof. 


\section{DISCLAIMER}

Portions of this document may be illegible in electronic image products. Images are produced from the best available original document. 
Printed

January 23, 1989
RFP-4204

UC-701 CHEMISTRY

DOE/OSTI-4500 (Interim 3)

RFP- -4204

DE89 008932

\section{PRODUCTION-SCALE DIRECT \\ OXIDE REDUCTION DEMONSTRATION}

\author{
T. J. Humiston \\ D. J. Santi \\ J. L. Long
}

R. L. Thomas, Editor

I. C. Delaney, Compositor
SUBJECT DESCRIPTORS

Buttons

Calcination

Calcium \& Magnesium

Chemical Analysis

Oxides and Reduction

Plutonium

X-Ray Diffraction
This document is PUBLICLY RELEASABLE iS ang Stiet

Authorizing Ofricial

Date:

$8 \cdot 24 \cdot 6+$
Prepared under Contract DE-AC04-76DPO3533

for the

Albuquerque Operations Office

U.S. Department of Energy
ROCKWELL INTERNATIONAL

AEROSPACE OPERATIONS

ROCKY FLATS PLANT

P. O. BOX 464

GOLDEN, COLORADO 80402-0464

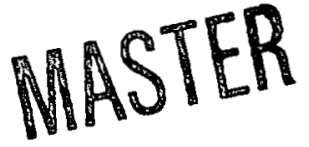


RFP-4204

\section{DO NOT MICROFILM THIS PAGE}




\section{CONTENTS}

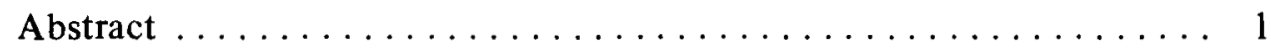

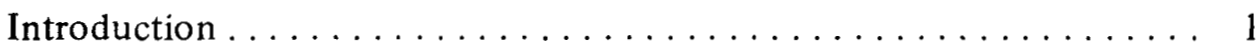

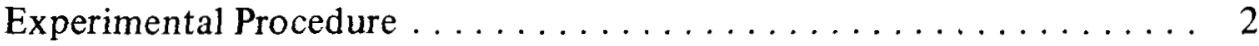

Salt Preparation and Handling. . . . . . . . . . . . . . 3

Calcium Metal Handling $\ldots \ldots \ldots \ldots \ldots \ldots \ldots \ldots \ldots$

Crucible Treatment ....................... 4

Plutonium Dioxide Preparation and Handling . . . . . . . . . 4

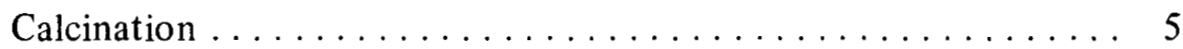

Direct Oxide Reduction Equipment $\ldots \ldots \ldots \ldots \ldots \ldots \ldots \ldots$

Direct Oxide Reduction $\ldots \ldots \ldots \ldots \ldots \ldots \ldots \ldots$

Results and Discussion $\ldots \ldots \ldots \ldots \ldots \ldots \ldots \ldots$

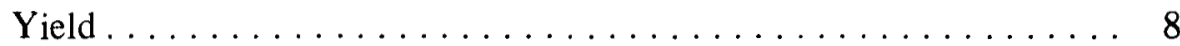

Crucible Failure. . . . . . . . . . . . . . . . . 11

Thermogravimetric Analysis of Feed Oxide. . . . . . . . . 12

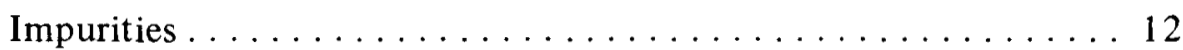

Conclusions. ........................ 13

Recommendations. .................... 14

References........................ 14

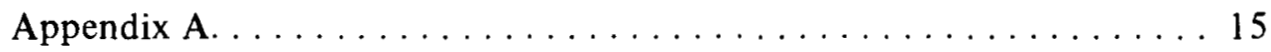

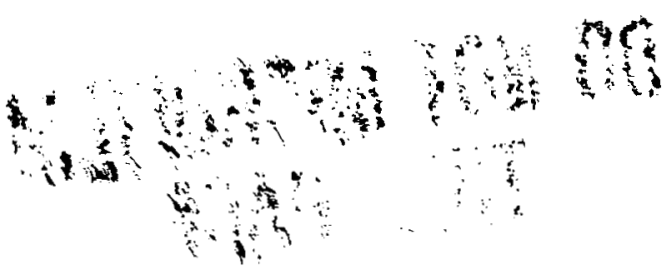




\section{A C K N O W LED G M E N T}

We wish to thank laboratory personnel for their assistance. Many times we requested and received services above and beyond the normal scope of laboratory operations.

Maintenance support helped us with special supplies, services, and equipment.

Material movement for this work was a particular challenge. Special thanks are due to Production Material Control for their efforts to maintain the supply and movement of material for this project.

The surface chemistry examinations would not have been possible without the support and helpful suggestions of Tony Rafalski, Dave Reifenberg, and Red Griffin of Physical Metallurgy. Their services are appreciated. 


\title{
PRODUCTION-SCALE DIRECT \\ OXIDE REDUCTION DEMONSTRATION
}

\author{
T. J. Humiston, D. J. Santi, and J. L. Long
}

\begin{abstract}
A detailed, statistically valid, examination of the direct oxide reduction parameters affecting process yield and purity was planned and executed. Guidelines for attaining yields approaching $100 \%$ are presented. Feed oxide, percent excess calcium, and stirrer design affected yield and product purity. Experiments were performed in production-scale equipment utilizing 800 grams of plutonium dioxide per charge.
\end{abstract}

\section{INTRODUCTION}

Pyrochemical Operations at Rocky Flats has performed Direct Oxide Reduction (DOR) routinely since 1982 when the technology was transferred from Los Alamos National Laboratory. The process reduces foundry-generated plutonium dioxide waste to an electrorefinable product. It performs well when using $\geqslant 85 \%$ plutonium oxide as feed. Overall average yield is $97 \%$. DOR is not a purification process; any impurities in the plutonium oxide, calcium chloride, and (to some extent) the reaction vessel contaminate the metal product.

DOR is a batch process that reduces non-pyrophoric plutonium dioxide to metal using calcium metal as the reducing agent in a molten calcium chloride salt flux. The fundamental chemical reaction is:

$$
\begin{aligned}
& \mathrm{PuO}_{2}+\underset{\mathrm{Ca}}{\mathrm{CaCl}_{2}} \stackrel{\mathrm{CaC}^{\circ} \mathrm{C}}{\mathrm{Pu}} \mathrm{Pu} \\
& +\mathrm{CaO} \text { (dissolved in } \mathrm{CaCl}_{2} \text { ) } \\
& + \text { Heat }
\end{aligned}
$$

The calcium oxide product readily dissolves into the salt to a maximum of 17 mole \%. The reaction is spontaneous (free energy of formation equal to $-47 \mathrm{kcal} / \mathrm{mole} \mathrm{PuO}_{2}$ ) and is probably controlled by the rate at which the calcium metal and plutonium dioxide are contacted. After the reaction and completion of stirring, the reaction products separate into distinct phases according to their relative specific gravities.

Although DOR has been a production process for several years, little effort has been expended to obtain pure metal from purified plutonium oxide. Because DOR will be used as a primary pyrochemical metal producing process, the Plutonium Recovery Project (PRP) requires detailed process design information. The DOR Demonstration was initiated to provide this information. Phase $\mathrm{I}$ provided information about the operating conditions, product yields, and product quality of the DOR process using purified plutonium dioxide. Phase I showed that metal produced by DOR requires electrorefining before being usable by the foundry. It also identified areas that could be improved, ultimately reducing the fraction of DOR product metal requiring electrorefining.

Phase II was initiated to:

1. Determine the fraction of DOR product metal that requires electrorefining prior to foundry use for blending.

2. Locate and verify a commercial source of acceptable reagent salt.

3. Define the DOR operating parameters that affect product metal yield and quality from purified plutonium dioxide.

Development work consisted of: Small-Scale Salt Examination (Phase IIA), Small-Scale Parameter Study (Phase IIB), and Production-Scale Parameter Verification (Phase IIC). This report describes Phase IIC.

The experimental plan for phase IIC was based upon the recommendations included in the report on the small-scale investigation of DOR. ${ }^{1}$ Seven recommendations resulted: 
1. Use fused (cast cakes) calcium chloride salt because it increases yield and reduces moisture absorption.

2. Use 4:1 salt-to-oxide ratio to reduce the salt waste generation without sacrificing yield.

3. Use $10 \%$ and $20 \%$ excess calcium because $25 \%$ excess calcium worked well in Phases IIA and IIB.

4. Use the historical positioning of loading the calcium above the oxide.

5. Further study the stirring speed and stirrer design because it had a significant effect on yield.

6. Consider hold time after reaction as a variable because of the scale dependency potential.

7. Consider "stirring in" versus "stirring out" of the metal because stirring in produced magnesium inclusions in the metal product and increased calcium in the button.
The variables to be investigated were selected from the small-scale studies on the basis of product yield, purity, and possible scale effects.

\section{EXPERIMENTAL PROCEDURE}

Six parameters were selected for further study in Phase IIC.

1. Feed plutonium dioxide

2. Percent excess calcium

3. Stirrer design

4. Stirrer speed

5. Stirrer position

6. Hold time after stirring.

Variable and constant parameters are given in Table 1.

TABLE 1. Phase IIC Parameters

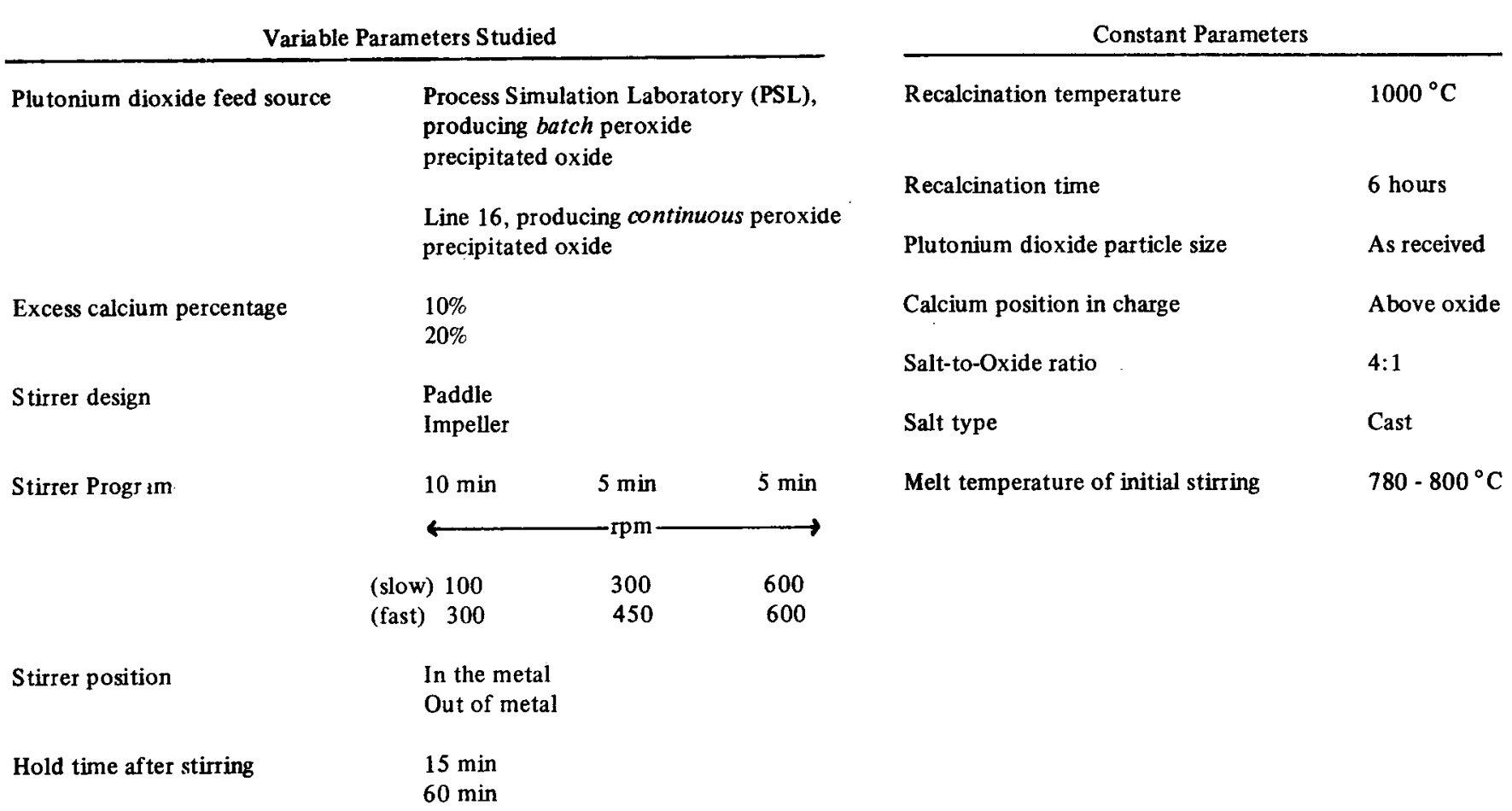


Feed type was included as a variable because of potential oxide supply problems and need for more information about the two types of oxide. The two types of plutonium dioxide of interest at Rocky Flats are from continuous peroxide precipitated oxide utilized in the current production process (Line 16) and batch peroxide precipitated oxide from the Process Simulation Laboratory (PSL).

An experimental matrix was developed to analyze the six variables. It was a Resolution Five fractional factorial experimental matrix of 32 runs to estimate the effect of the variables on process variation as well as the mean. Process variation is the "spread" or scatter in the data around the mean value. A Resolution Five plan does not confound (cause to be inseparable) main effects and two-way interactions, but does confound two-way interactions with three-way interactions.

The plan was then randomized to eliminate potential for confounding the variable effects with the processing order. For example, when one operator performs experiments and another completes the tests, are the differences in results caused by variations of the experiment or handling by the operators? Randomization greatly reduces potential effects of outside factors.

\section{Salt Preparation and Handling}

Because the small-scale investigation ${ }^{1}$ determined that Fisher anhydrous (C-77) calcium chloride salt had fewer impurities and less water content than other salt supplies, it was used for Phase IIC. The salt was dried in a convection oven at $225^{\circ} \mathrm{C}$, cast into salt cakes, and stored in a vacuum drying oven at $225{ }^{\circ} \mathrm{C}$. One cake for each run was cast with a large center cavity and the other was cast as a solid cake. The combined weight of a two-cake charge was approximately 3200 grams. The cake with the cavity was loaded with calcium metal, providing distinct separation between the calcium and plutonium dioxide. See Figure 1. Before

FIGURE 1. Calcium Chloride Salt Cakes and Calcium Metal Granules

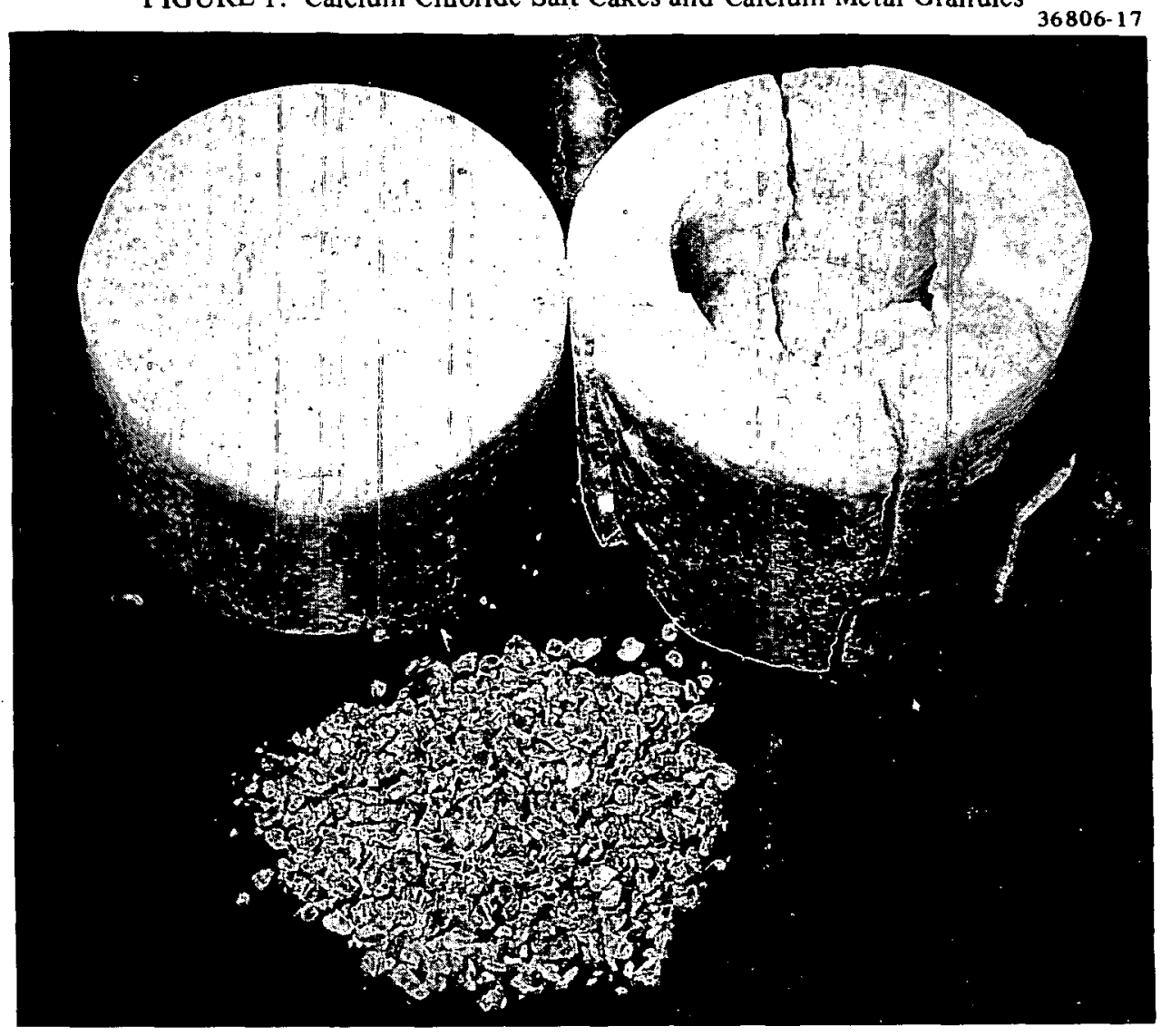


loading a DOR charge, the cakes were taken from the drying oven and placed into a desiccator to cool, then weighed, bagged, and sealed under positive-pressure argon.

\section{Calcium Metal Handling}

The calcium metal supply was kept in a sealed pressure vessel at approximately 20-30 psig argon to prevent reaction with moisture. Two levels of calcium excess ( 10 and $20 \%$ by stoichiometry) were used in the DOR experiments. Calcium granules are shown in Figure 1.

\section{Crucible Treatment}

High-density magnesium oxide crucibles are used as the primary reaction chamber for DOR. The crucibles (Figure 2) were approximately 12 inches high by $53 / 16$ inches inner diameter with a 3-3/4-inch spherical radius bottom; they were stored in a vacuum drying oven. Before use, the crucibles were baked at $225^{\circ} \mathrm{C}$ (at least 24 hours, usually seven or more days), placed in a desiccator to cool, and then bagged in positive-pressure argon.

\section{Plutonium Dioxide Preparation and Handling}

The plutonium dioxide was produced via peroxide precipitation. Precipitation occurs when hydrogen peroxide solution is added to concentrated plutonium nitrate solution, producing solid plutonium peroxide. To enhance filtration by enlarging particle size, a sulfate solution is added with the peroxide. The peroxide precipitation acts as a purification process because the peroxide selectively precipitates plutonium while the impurities are washed through with the filtrate. However, if the wash (with nitrate solution) at the end of filtration is incomplete, some impurities stay with the peroxide compound. Any impurities not removed in calcination remain in the DOR product metal. After filtration, the plutonium peroxide was calcined at $450{ }^{\circ} \mathrm{C}$, producing plutonium dioxide containing varying amounts of sulfates, nitrates, water, and carbon.

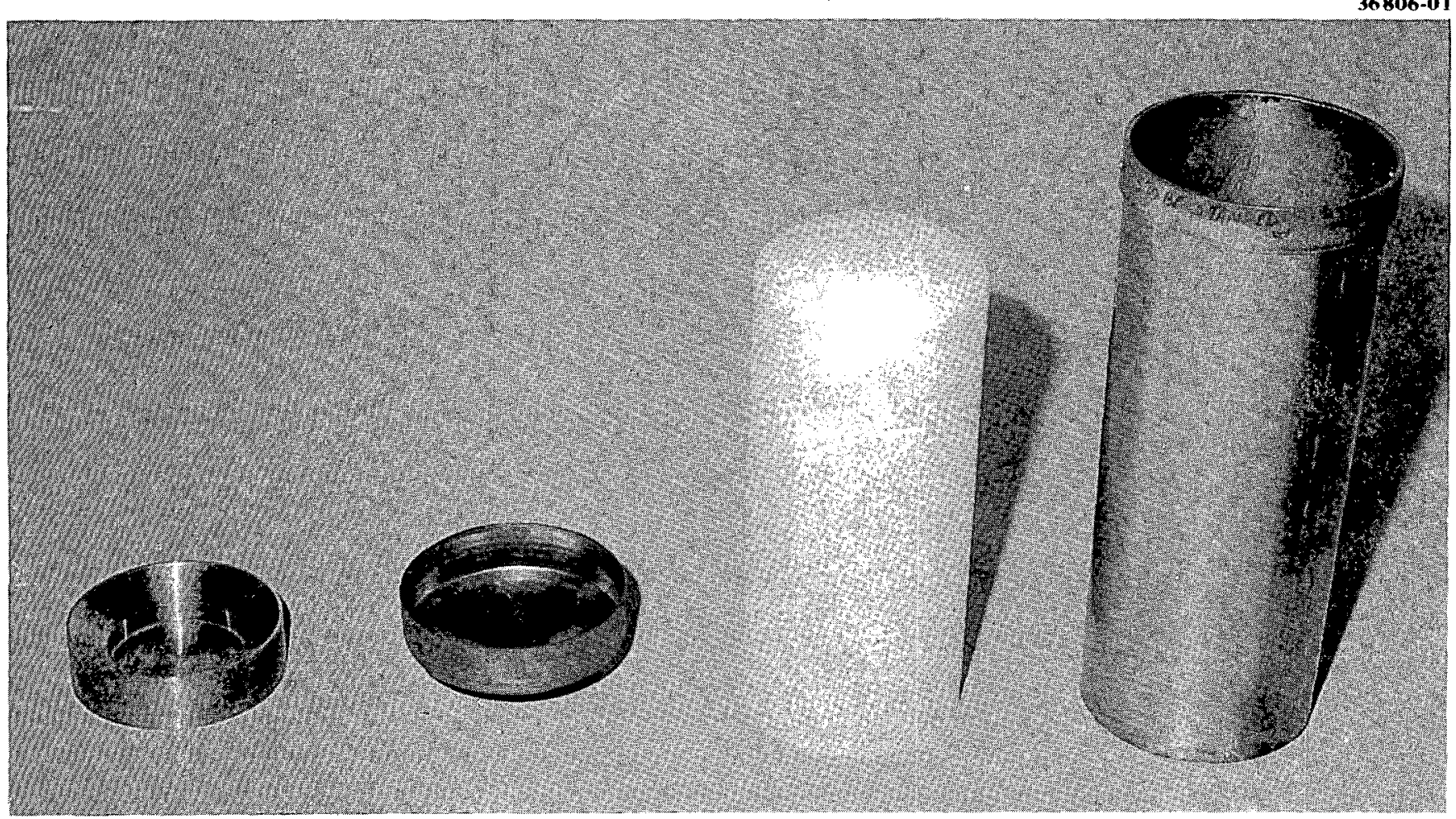


The oxides were calcined again at $1000^{\circ} \mathrm{C}$. After recalcination, the oxide was sent for calorimetry. Then, it was heated to $210^{\circ} \mathrm{C}$ in the same calcination furnace, weighed, and stored in a 16-ounce wide-mouth glass jar with a vinylite lined screw cap.

\section{Calcination}

A second, high-temperature, calcination step is required to remove carbon, remaining sulfates, nitrates, water, and other impurities after calcinations at $450{ }^{\circ} \mathrm{C}$. The plutonium dioxide was recalcined at $1000^{\circ} \mathrm{C}$ for six hours in an air atmosphere and stirred at least hourly. Recalcination was performed in a Fisher Isotemp Ashing furnace Model 495 equipped with microprocessor control (Figure 3 ). Air is preheated and exchanged through the chamber three times per minute, producing high-temperature uniformity and extra air for good reaction kinetics. The chamber is made of molded alumino silicate ceramic with low thermal mass and self-insulating chamber walls for fast heatups and cooldowns. Because of their construction, the chamber walls have less potential for partial disintegration, thus eliminating aluminum-silicon addition to the plutonium oxide during calcination.

In Phase I, an Inconel boat held the oxide; and iron, nickel, and chromium were introduced during the recalcination process. The plutonium dioxide corroded the boats to the extent that the Inconel flaked into the oxide. Results from previous studies indicated that platinum remains inert to the plutonium dioxide and its contaminants at high temperatures. A platinum recalcination vessel (boat) along with platinum coated tongs for stirring (Figure 3 ) were used for recalcination in Phase IIC.

\section{Direct Oxide Reduction Equipment}

The DOR experiments were performed in stationary furnaces (cells) with 5-3/4-inch inner diameter Inconel wells as the reaction chambers. The outer furnace cans containing the heating coils included a water-cooled copper heat sink in case of reagent

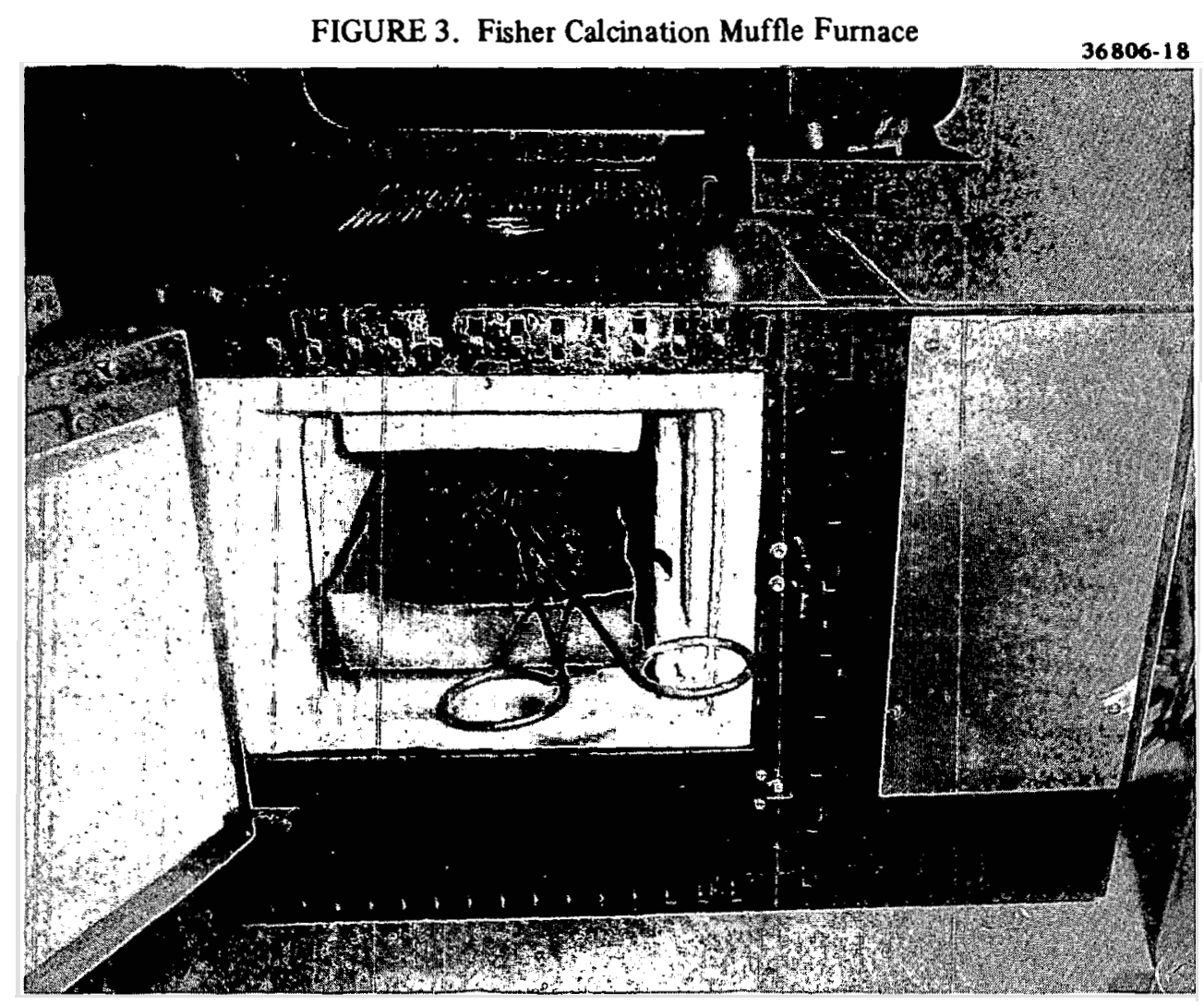


leakage from the Inconel well. See Figure 4.

The outer furnace can is vented to the glovebox. Thus, in the event of inner can failure, pressure would be relieved into the glovebox.

The cells were equipped with typical Rocky Flats DOR cell heads and stirring apparatus. The cell heads seal the inner reaction chamber from the glovebox atmosphere (flow-through nitrogen system) by an O-ring machined into the furnace top flange. Figure 5 shows a cell head in the loaded configuration (DOR charge in the furnace) before the reagents have melted. Notice the optical encoder on the motor pulley. Encoders register the revolutions per minute of the stirrers. They are slipped over the top of the steel stirrer shafts like a bearing after the salt becomes molten and the stirrers are lowered. The electronics that drive the motor and receive the encoder signals provide precise speed and time control for this step-type stirring program. Speed is actuated through the stirrer by an O-ring used as a belt coupled with pulleys on the motor and stirrer shaft.

The tantalum stirrers are screwed into $3 / 4$-inch stainless steel shafts. The steel shaft penetrates the cell head through an oil seal contained within a bearing retainer flange. Two types of stirrers were used: Flat paddle and opposing-pitch impeller. The paddles are approximately $3.3 / 4$ inches at the widest point. The 2-inch-diameter impeller stirrers are 12 to 13 inches long. Figure 6 shows both types.

FIGURE 4. Lower Half of Stationary Furnace

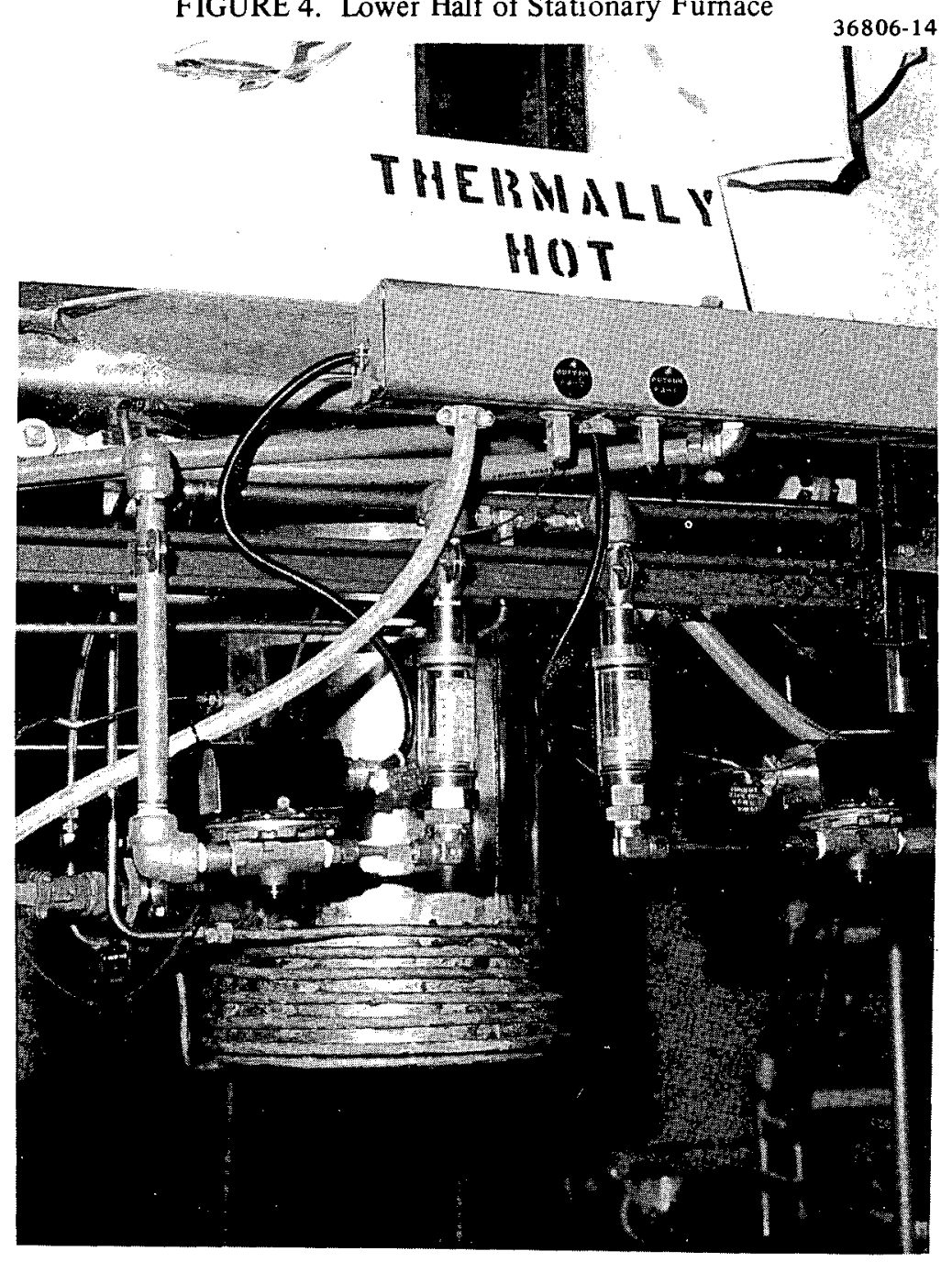




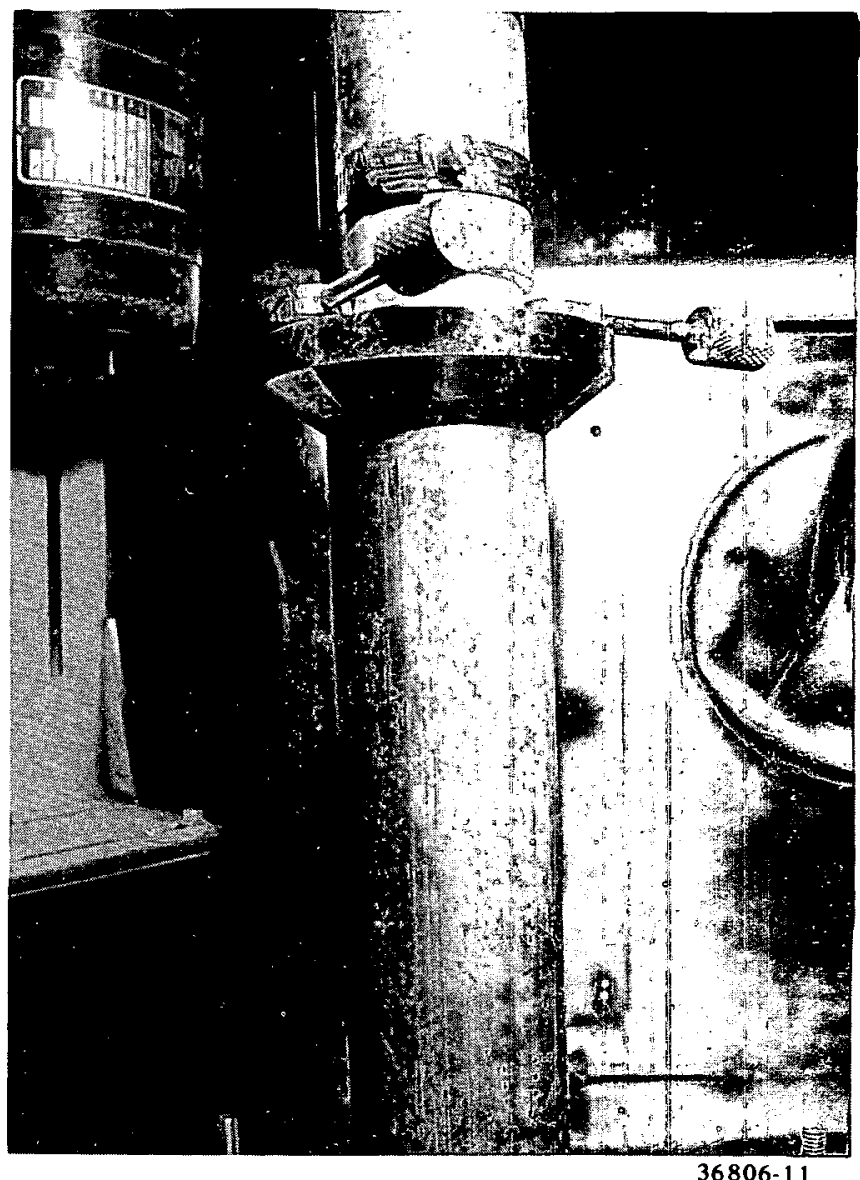

FIGURE 5. DOR Cell Head

\section{Direct Oxide Reduction}

Prior to each experiment, the equipment was cleaned and checked. The tantalum stirrers were leached after each run in $1 N \mathrm{HCl}$ to remove holdup material and salt residue.

Figure 2 shows the crucible and back-up cans before assembly.

The back-up can assembly containing the crucible was moved to the stationary cell area along with the plutonium dioxide and reagents. The assembly without reagents was placed in the cell, and the stirrer was lowered and positioned to the proper height, less than $1 / 4$ inch from the bottom for an "in-the-metal" run; for an "out-of-metal" run, the flat paddle was positioned $3 / 4$ inch from the bottom. The reagents were kept in bags under argon pressure in the gloveline before being loaded.

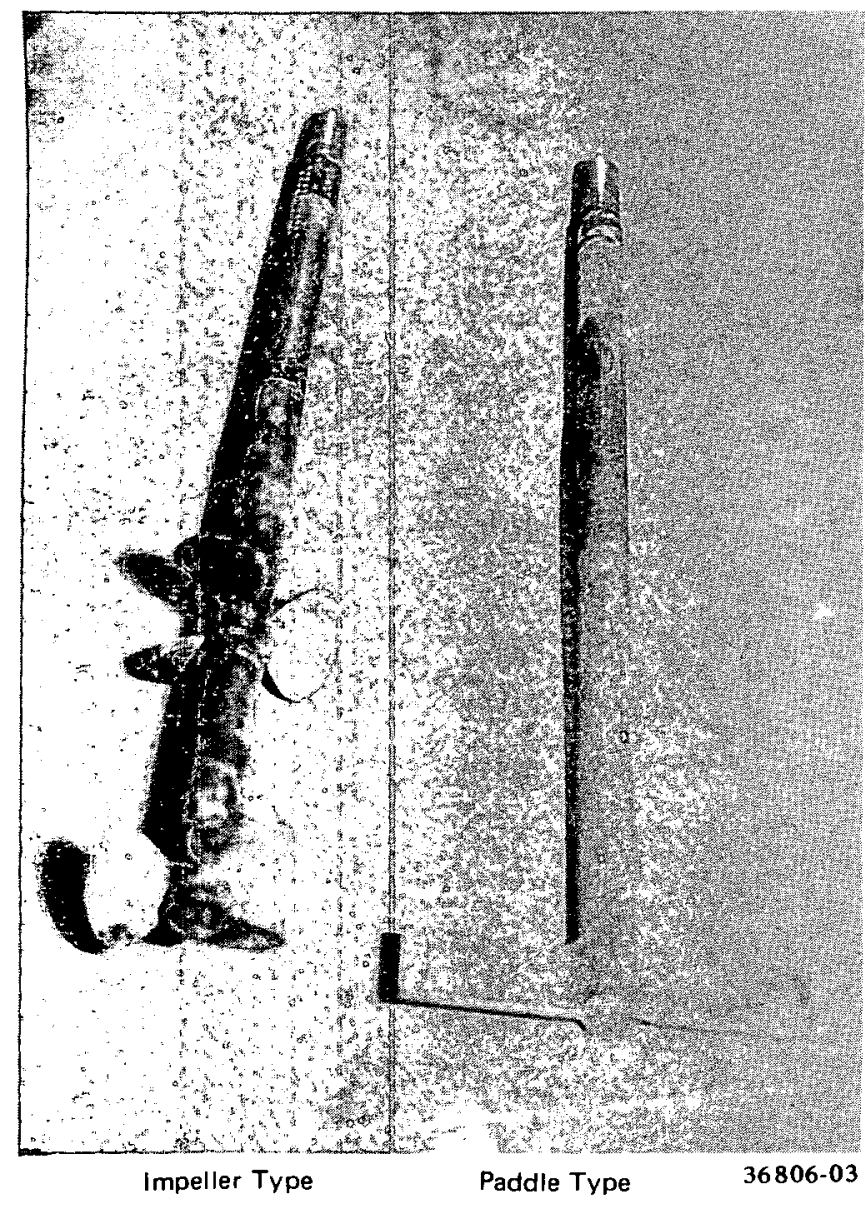

FIGURE 6. Stirrers

First, the plutonium dioxide was poured slowly (to minimize dusting) from a water-tight jar into the crucible. A salt cake (with cavity) was carefully lowered onto the oxide, and calcium metal was dropped into the cake cavity. A solid salt cake was then placed on the calcium/salt cake. The entire can assembly with reagents was lowered into the stationary furnace and the cell head was sealed to the furnace. The chamber was evacuated to approximately two millibar and backfilled with argon to approximately 1100 millibar three times before heating.

A conservative heating program was used to avoid crucible failure during heatup.

Approximately 45 minutes after the furnace coil reached $1000^{\circ} \mathrm{C}$, the salt became molten, the stirrer and thermocouple were lowered, and one of the two stirring programs was initiated. 
After stirring and proper hold time, the furnace was cooled at a controlled rate of $200^{\circ} \mathrm{C}$ per hour to $600^{\circ} \mathrm{C}$ outside temperature (inside temperature $=$ $700^{\circ} \mathrm{C}$ ).

After cooling to a safe temperature, the contents were sent to the breakout area where the backup cans were separated from the crucible and set aside. To aid breakout, the stainless steel backup cans were made with a three- to five-degree taper.

When a ceramic crucible broke during a run, the entire charge was tipped upside down and slammed against the glovebox floor. The taper in the backup can along with the steel crucible support weighing more than two $\mathrm{kg}$ helped force the contents from the can.

The crucible was broken from the charge, leaving the salt and plutonium button. The button normally rested on the salt's bottom surface. Any

FIGURE 7. DOR Charge After Experiment

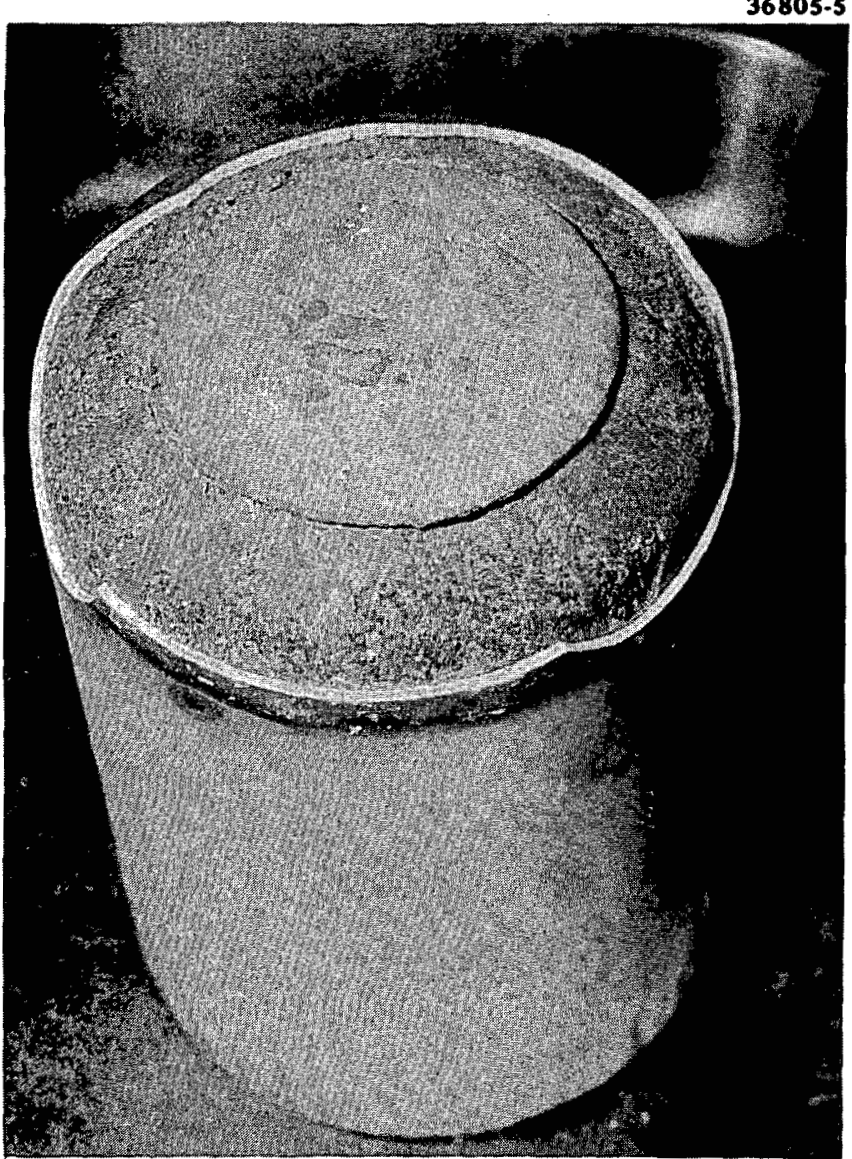

salt or other residues were either brushed or hammered from the button.

The button was sampled three times. The first was a 10- to 15-gram drill sample from the top surface. The second was from the bottom. The last sample was pie shaped, weighing 5 to 35 grams. It was hack sawed from the edge and used for metallography data. Photomicrographs were taken at the top, middle, and bottom of the latter sample. After sampling, the button and salt samples were sent for non-destructive assay.

\section{RESULTS AND DISCUSSION}

General breakouts of the Phase IIC experiments were simple. The crucibles rarely failed unless the cool-down rate exceeded $200{ }^{\circ} \mathrm{C}$ per hour. See the Crucible Failure section of this report. Figure 7 depicts a typical DOR charge after reaction; it is shown in the inverted position with the bottom of the crucible broken away. Notice the distinct phases of salt and button. The top surface is shown in Figure 8 . The impressions left by the salt are clearly visible.

\section{Yield}

Yield was calculated by multiplying the product button's weight by its purity (determined by

FIGURE 8. DOR Product Button Top Surface

36805-14

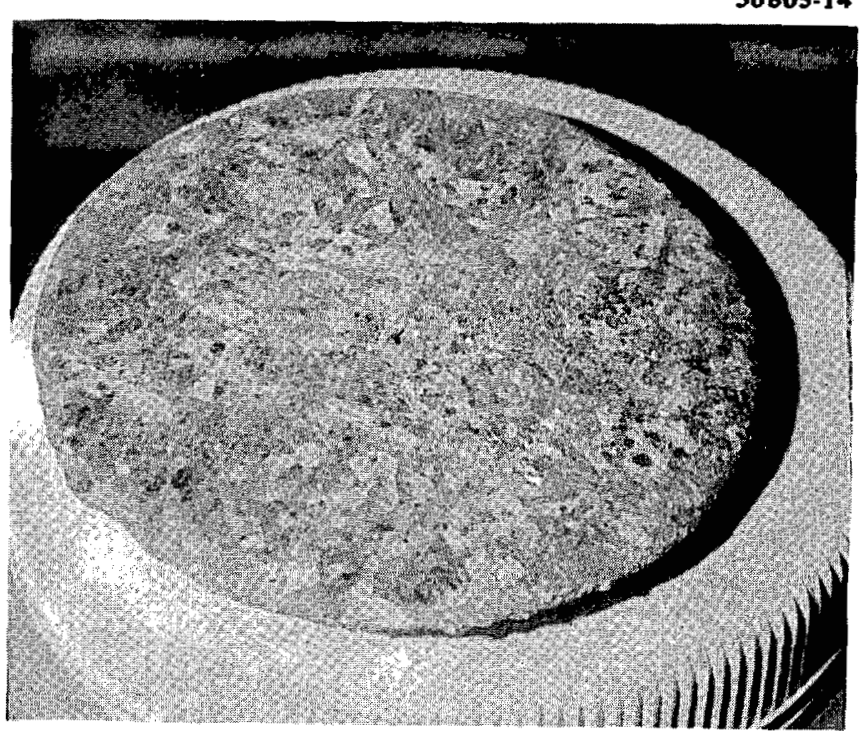


calorimetry) and then dividing by the oxide feed weight and purity. A linear least squares regression analysis was performed. Plutonium oxide type, percent excess calcium, and stirrer design were shown to affect the yield. Other variables and their interactions did not influence yield at the 95\% confidence level.

Overall, the yield for the entire set of experiments averaged $86.1 \%$. Table 2 shows the variables used in each experiment and corresponding yields. The three variables that affected yield at the $95 \%$ confidence level are:
1. Line 16 (continuously precipitated) oxide performed better than PSL (batch precipitated) oxide.

2. $20 \%$ excess calcium demonstrated higher yields than $10 \%$ excess calcium.

3. The paddle stirrer achieved higher yields than the impeller stirrer.

A statistical least squares analysis is provided in Table 3. For the main effects, if the overall average yield of $86.1 \%$ is subtracted from the

TABLE 2. Phase IIC Parameters and Yield Results

\begin{tabular}{|c|c|c|c|c|c|c|c|c|c|c|c|}
\hline $\begin{array}{l}\text { DOR } \\
\text { EXP. }\end{array}$ & $\begin{array}{l}\text { Oxide } \\
\text { Type* }\end{array}$ & $\begin{array}{l}\text { Hold } \\
\text { Time } \\
\text { (min) }\end{array}$ & $\begin{array}{l}\text { Stirrer } \\
\text { Design }\end{array}$ & $\begin{array}{c}\text { Stirrer } \\
\text { Position }\end{array}$ & $\begin{array}{l}\text { Stirring } \\
\text { Program }\end{array}$ & $\begin{array}{c}\text { Excess } \\
\mathrm{Ca} \\
(\%)\end{array}$ & $\begin{array}{c}\text { Button } \\
\text { (g) }\end{array}$ & $\begin{array}{c}\text { Button } \\
\text { Purity } \\
(\%)\end{array}$ & $\begin{array}{l}\text { Oxide } \\
(\mathrm{g})\end{array}$ & $\begin{array}{c}\text { Oxide } \\
\text { Purity } \\
(\%)\end{array}$ & $\begin{array}{c}\text { Yield** } \\
(\%)\end{array}$ \\
\hline 1 & PSL & 60 & PAD & Out & Slow & 20.00 & 685.00 & 0.9955 & 799.40 & 0.8847 & 96.42 \\
\hline 2 & L16 & 60 & IMP & In & Fast & 10.00 & 674.20 & 0.9988 & 800.00 & 0.8720 & 96.53 \\
\hline 3 & PSL & 60 & IMP & In & Slow & 20.00 & 525.90 & 0.9820 & 800.00 & 0.8758 & 73.71 \\
\hline 5 & PSL & 15 & PAD & Out & Fast & 20.00 & 700.00 & 0.9810 & 800.00 & 0.8821 & 97.31 \\
\hline 6 & PSL & 15 & PAD & In & Slow & 20.00 & 609.00 & 0.9847 & 800.00 & 0.8837 & 84.83 \\
\hline 7 & PSL & 60 & PAD & In & Fast & 20.00 & 690.80 & 0.9943 & 800.00 & 0.8818 & 97.37 \\
\hline 8 & $L 16$ & 60 & IMP & Out & Slow & 10.00 & 596.50 & 0.9859 & 800.00 & 0.8775 & 83.77 \\
\hline 9 & PSL & 15 & IMP & In & Fast & 20.00 & 630.80 & 0.9680 & 800.10 & 0.8773 & 86.99 \\
\hline 10 & PSL & 15 & PAD & Out & Slow & 10.00 & 674.80 & 0.9961 & 800.00 & 0.8848 & 94.96 \\
\hline 11 & PSL & 15 & PAD & In & Fast & 10.00 & 614.40 & 0.9135 & 800.00 & 0.8830 & 79.45 \\
\hline 13 & L16 & 60 & IMP & Out & Fast & 20.00 & 536.40 & 0.9751 & 800.00 & 0.8788 & 74.40 \\
\hline 14 & L16 & 15 & IMP & In & Fast & 20.00 & 723.10 & 0.9946 & 800.00 & 0.8825 & 99.90 \\
\hline 15 & L16 & 60 & IMP & In & Slow & 20.00 & 654.70 & 0.9879 & 800.00 & 0.8772 & 92.17 \\
\hline 16 & L16 & 60 & PAD & Out & Slow & 20.00 & 695.20 & 0.9881 & 800.00 & 0.8781 & 97.79 \\
\hline 17 & PSL & 60 & IMP & In & Fast & 10.00 & 568.40 & 0.9318 & 800.00 & 0.8806 & 75.18 \\
\hline 18 & PSL & 15 & IMP & In & Slow & 10.00 & 395.50 & 0.9437 & 800.00 & 0.8792 & 53.06 \\
\hline 19 & L16 & 15 & IMP & Out & Fast & 10.00 & 570.20 & 0.9872 & 800.00 & 0.8819 & 79.79 \\
\hline 20 & L16 & 15 & IMP & In & Slow & 10.00 & 674.90 & 0.9733 & 800.10 & 0.8744 & 93.89 \\
\hline 21 & L16 & 15 & PAD & Out & Slow & 10.00 & 545.80 & 0.9909 & 800.00 & 0.8740 & 77.35 \\
\hline 22 & PSL & 15 & IMP & Out & Fast & 10.00 & 544.70 & 0.9547 & 800.00 & 0.8778 & 74.05 \\
\hline 23 & L16 & 15 & PAD & In & Slow & 20.00 & 703.60 & 0.9868 & 800.00 & 0.8906 & 97.45 \\
\hline 24 & L16 & 15 & PAD & Out & Fast & 20.00 & 700.00 & 0.9999 & 800.00 & 0.8758 & 99.90 \\
\hline 25 & L16 & 60 & PAD & In & Fast & 20.00 & 702.50 & 0.9892 & 800.00 & 0.8680 & 99.90 \\
\hline 26 & PSL & 15 & IMP & Out & Slow & 20.00 & 611.20 & 0.9838 & 800.00 & 0.8772 & 85.68 \\
\hline 27 & L16 & 60 & PAD & Out & Fast & 10.00 & 663.90 & 0.9852 & 800.00 & 0.8747 & 93.47 \\
\hline 28 & PSL & 60 & IMP & Out & Slow & 10.00 & 440.40 & 0.9534 & 800.00 & 0.8794 & 59.68 \\
\hline 29 & PSL & 60 & PAD & In & Slow & 10.00 & 646.70 & 0.9929 & 800.00 & 0.8762 & 91.60 \\
\hline 30 & PSL & 60 & PAD & Out & Fast & 10.00 & 622.40 & 0.9909 & 800.00 & 0.8782 & 87.78 \\
\hline 31 & PSL & 60 & IMP & Out & Fast & 20.00 & 498.40 & 0.9692 & 800.00 & 0.8742 & 69.07 \\
\hline 32 & L16 & 60 & PAD & In & Slow & 10.00 & 646.90 & 0.9892 & 800.00 & 0.8789 & 91.01 \\
\hline 33 & L16 & 15 & PAD & In & Fast & 10.00 & 673.00 & 0.9797 & 800.00 & 0.8754 & 94.15 \\
\hline 34 & L16 & 15 & IMP & Out & Slow & 20.00 & 547.20 & 0.9887 & 800.00 & 0.8810 & 76.76 \\
\hline
\end{tabular}

*Line 16 , continuous peroxide precipitated.

PSL, batch precipitated.

** Yield $=\{$ button weight $X$ button purity $\} /\{$ oxide feed weight $\times$ oxide purity $\}$. 
TABLE 3. Yield Comparison - Main Effects

\begin{tabular}{|c|c|c|c|c|c|c|c|}
\hline $\begin{array}{c}\text { L16 } \\
\text { Oxide } \\
(\%)\end{array}$ & $\begin{array}{l}\text { PSL } \\
\text { Oxide } \\
(\%)\end{array}$ & & $\begin{array}{c}\text { Impeller } \\
\text { Stirrer } \\
(\%) \\
\end{array}$ & $\begin{array}{c}\text { Paddle } \\
\text { Stirrer } \\
(\%) \\
\end{array}$ & & $\begin{array}{c}10 \% \\
\text { Excess Ca } \\
(\%)\end{array}$ & $\begin{array}{c}20 \% \\
\text { Excess Ca } \\
(\%) \\
\end{array}$ \\
\hline 96.53 & 96.42 & & 96.53 & 96.42 & & 96.53 & 96.42 \\
\hline 83.77 & 73.71 & & 73.71 & 97.31 & & 83.77 & 73.71 \\
\hline 74.40 & 97.31 & & 83.77 & 84.83 & & 94.96 & 97.31 \\
\hline 99.90 & 84.83 & & 86.99 & 97.37 & & 79.45 & 84.83 \\
\hline 92.17 & 97.37 & & 74.40 & 94.96 & & 75.18 & 97.37 \\
\hline 97.79 & 86.99 & & 99.90 & 79.45 & & 53.06 & 86.99 \\
\hline 79.79 & 94.96 & & 92.17 & 97.79 & & 79.79 & 74.40 \\
\hline 93.89 & 79.45 & & 75.18 & 77.35 & & 93.89 & 99.90 \\
\hline 77.35 & 75.18 & & 53.06 & 97.45 & & 77.35 & 92.17 \\
\hline 97.45 & 53.06 & & 79.79 & 99.90 & & 74.05 & 97.79 \\
\hline 99.90 & 74.05 & & 93.89 & 99.90 & & 93.47 & $97: 45$ \\
\hline 99.90 & 85.68 & & 74.05 & 93.47 & & 59.68 & 99.90 \\
\hline 93.47 & 59.68 & & 85.68 & 91.60 & & 91.60 & 99.90 \\
\hline 91.01 & 91.60 & & 59.68 & 87.78 & & 87.78 & 85.68 \\
\hline 94.15 & 87.78 & & 69.07 & 91.01 & & 91.01 & 69.07 \\
\hline 76.76 & 69.07 & & 76.76 & 94.15 & & 94.15 & 76.76 \\
\hline 90.51 & 81.70 & a & 79.66 & 92.55 & a & 82.86 & 89.35 \\
\hline 8.82 & & b & 13.09 & & b & 6.49 & \\
\hline 4.41 & & c & 6.54 & & c & 3.25 & \\
\hline
\end{tabular}

Yield $=[$ (button weight $) \times($ purity $)] /[$ (oxide feed weight $) \times($ oxide purity $)]$

a Average yields calculated from the columns above.

${ }^{b}$ ifference between the two average yields in (a) above.

${ }^{c}$ Differences in (b) divided by two.

average yield of the individual parameter, an estimate of that parameter's effect on the process yield can be calculated. For example, comparing Line 16 with PSL oxide:

Line $16 \quad 90.5-86.1=4.4 \%$
(continuous peroxide precipitated)

PSL

(batch precipitated)

$81.7-86.1=-4.4 \%$

This means the process yield of $86.1 \%$ could be increased approximately $4.4 \%$ by using only Line 16 oxide or that a decrease of $4.4 \%$ would be realized by using PSL oxide. The same holds true for the other main effects. Using the paddle stirrer would improve the $86.1 \%$ yield $6 \%$, and $20 \%$ excess calcium would increase the yield $3 \%$.

The superior performance of Line 16 oxide versus PSL oxide is difficult to explain. The only major difference is that Line 16 oxide has a larger crystallite size after recalcination. Both oxides were produced via peroxide precipitation, one continuous, the other batch. Either there is a direct correlation between crystallite size and yield, or there are other differences in the two oxides. This should be resolved before deciding which to use. The yield difference may be suspect because some of the PSL oxide contained a small amount of water, which could have depressed the yields. See Thermogravimetric Analysis, this report.

A $13 \%$ greater average yield performance of the paddle stirrer over the impeller stirrer can be explained by the physical design difference. The paddle stirrers had blades nearly double those of the impeller stirrers.

Twenty percent excess calcium performed better than $10 \%$ excess calcium, probably because the latter was inadequate to reduce the full amount of plutonium oxide and other undesirable oxides. The numbers of calcium buttons produced and when they were produced support this argument. For the 16 runs performed with $10 \%$ excess 
calcium, seven produced calcium buttons. This compares with 14 calcium buttons produced in 16 runs using $20 \%$ excess calcium. A calcium button present at the end of a run indicates: (1) inadequate contact between oxide and calcium or (2) more than the required amount of calcium. For the seven runs that produced calcium buttons using $10 \%$ excess calcium, six were performed with impeller stirrers. This suggests the impeller stirrer provides insufficient agitation and supports the superior yield performance of the paddle stirrer.

A model based on the results of the linear least squares regression was calculated as follows:

$$
\begin{aligned}
\text { Yield } & =86.1(\text { average yield }) \\
& -4.4 \cdot(\text { feed oxide }) \\
& +3.2 \cdot(\text { excess calcium }) \\
& -6.5 \cdot(\text { stirrer design })
\end{aligned}
$$

This equation summarizes the quantitative yield results stated previously about Table 3 .

Theoretically, the quantitative effects are additive, so more than $14 \%$ could be added to the $86.1 \%$ overall average yield if the best parameters are selected from those that affect yield. Other factors, such as water in the reagents, glovebox atmosphere, and argon, tend to decrease the yield slightly. A yield greater than $100 \%$ is not possible, but yields approaching that value can be achieved by choosing the best parameters according to the model.

Based on the results of the least squares regression, two experiments were selected from the experimental plan with the "best" parameters: Line 16 continuous precipitated oxide, $20 \%$ excess calcium, fast stirrer program, and a paddle stirrer. Yields for both experiments were $99.9 \%$.

Additional verification of the additive principle was supported by two experiments performed after the completion of Phase IIC. These runs used the best parameters available based on preliminary results of Phase IIC. Yields of $99 \%$ and $98 \%$ were achieved. The same fixed parameters were used as in Phase IIC. Following is a listing of the parameters not fixed in Phase IIC used to achieve the respective yields:

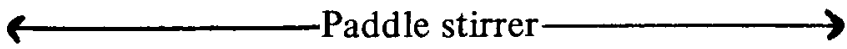

$\longleftrightarrow<1 \mathrm{~min}$. ramp to $600 \mathrm{rpm}$ stirring $\longrightarrow$

Line 16 oxide

PSL oxide

$50 \%$ Excess calcium

$25 \%$ Excess calcium $15 \mathrm{~min}$. hold timeStirred "in the metal"

\section{Crucible Failure}

No crucibles failed in Phase IIC from heat of reaction thermal shock. Four crucibles did fail for other reasons. Two occurred with a cooling rate exceeding $200^{\circ} \mathrm{C}$ per hour. Faster cooling rates should be used only after the reaction products are frozen at $\leqslant 700{ }^{\circ} \mathrm{C}$ inside temperature. Two failures occurred because of operator error. Yield was not affected by any of the failures.

DOR crucibles can fail from heat of reaction thermal shock. Figure 9 illustrates this phenomenon, which occurred in a run performed after Phase IIC. Most likely, failure was caused by a short stirring ramp to $600 \mathrm{rpm}$, whereby most of the heat of reaction was transferred to the crucible producing stresses above the limits of the magnesium oxide. The crucible shown was separated into two halves; the right half is the bottom of the charge showing the frozen salt, and the left is the top of the crucible. Looking carefully at the left half, notice a ring of salt pointing to the center of the crucible just below the top, indicating the salt level at the highest rate of stirring. Crucible failure occurred just below this ring (top edge).

The primary difference between experiments in Phase IIC and the subsequent experiment where the crucible failed from heat of reaction was the stirring program. During Phase IIC, the reactants were stirred 15 minutes at less than $600 \mathrm{rpm}$ before reaching the maximum speed. In contrast, the stirring program of the failed crucible experiment consisted of a step-like jump to $600 \mathrm{rpm}$ from the 


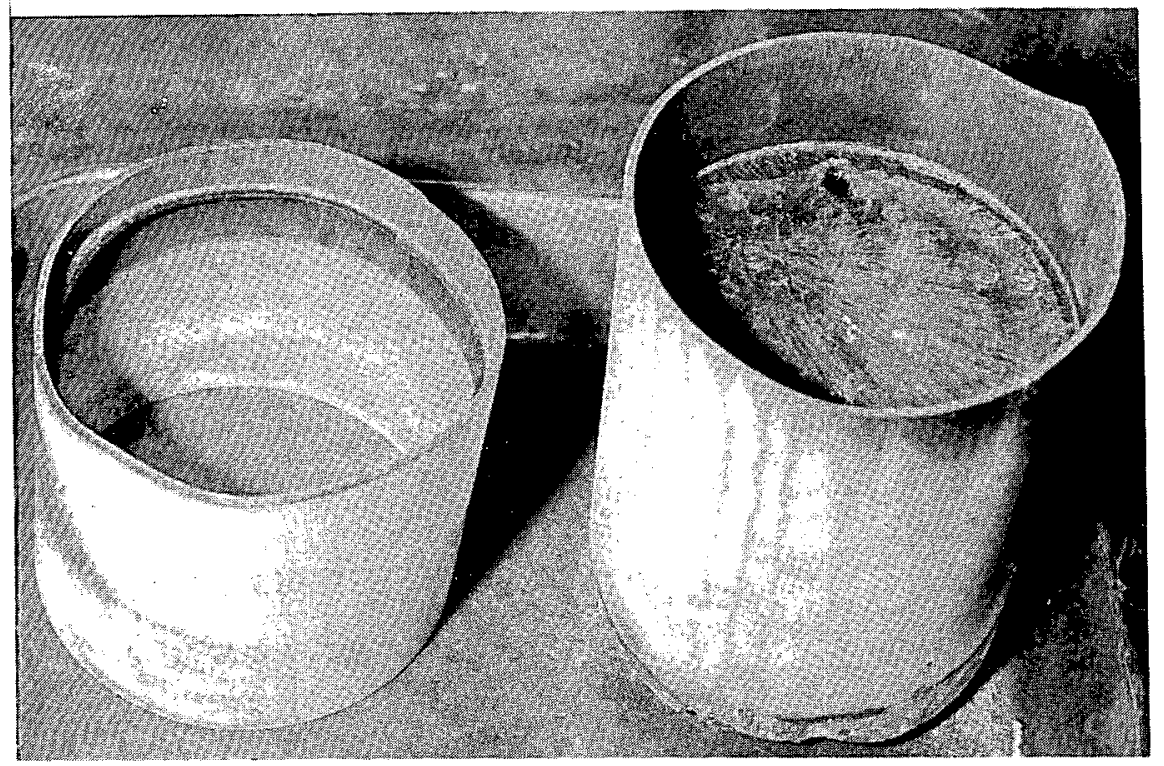

FIGURE 9. Crucible After DOR Showing Reaction Thermal Shock

$36805-9$

static condition. By gradually increasing speed over a few minutes to the maximum, the heat of reaction can be spread out, thus reducing the shock to the crucible.

Theoretically, approximately $141 \mathrm{kcal}$ are released to the system. This corresponds to a $151{ }^{\circ} \mathrm{C}$ temperature increase given the conditions of charge size and salt composition- -in this case, 800 grams plutonium oxide, 3200 grams $99.2 \%$ pure calcium chloride, and 284 grams calcium metal ( $20 \%$ excess). This energy release should be spread out over several minutes to prevent crucible failure.

Identifying the type of crucible failure is accomplished by examining the cracks. Typically, cracks caused by improper equipment or reagent handling or from an overly aggressive heating or cooling ramp appear as a single, vertical, nonsymmetric crack. In contrast, evidence of heat of reaction thermal shock failure shows a single, uniform, circumferential crucible crack just below the maximum salt height.

\section{Thermogravimetric Analysis of Feed Oxide}

As part of the experimental procedure, a five-gram control sample of the feed oxide was taken just before loading into the crucible. It was submitted for Thermogravimetric Analysis (TGA) to determine whether the oxide had absorbed any water during storage after recalcination.

Five of the 32 samples exhibited moisture pickup; those five samples used PSL oxide as feed. The moisture pickup could have resulted from:

1. Improper handling of oxide during packaging.

2. Poor storage container seal.

3. Excessive time sampling the oxide.

4. Improper handling/splitting of the sample.

Statistically, there was an average $8.8 \%$ difference in yield between PSL oxide and Line 16 oxide. In two experiments using PSL oxide, the difference in yields from two corresponding Line 16 experiments is far greater than the $8.8 \%$ average. It appears that an outside effect, probably water, depressed the yields. Therefore, proper handling is essential.

\section{Impurities}

DOR product buttons produced in Phase IIC were sampled and analyzed for 23 elements. These 
elements are of interest to the foundry and can have an impact on down-stream processes such as electrorefining. See Appendix A. Like the statistical yield calculations, a linear least squares regression analysis was performed pertaining to impurities.

The analysis showed that six impurities were affected by the DOR process: Aluminum, gallium, iron, nickel, chromium, and carbon. Calcium and magnesium were excluded from analysis because of high variability in the data. The main effects on impurities in the metal product were caused by the same parameters that affected yield: feed oxide, stirrer design, and excess calcium. Feed oxide was the most dominant, showing an effect on all six of the impurities above. PSL oxide increased the average concentration of aluminum and carbon in the product metal, whereas Line 16 increased concentrations of aluminum, gallium, iron, nickel, and chromium.

\section{CONCLUSIONS}

Yield for the 32 experiments in Phase IIC averaged $86.1 \%$. Three main effects affected yield: feed oxide type, percent of excess calcium, and stirrer design. A statistical model was developed; it predicts with $95 \%$ confidence that best yields can be attained with the following main effects:

\section{Line 16 (continuously precipitated) plutonium oxide as feed}

\section{2. $20 \%$ excess calcium}

\section{Flat paddle stirrer}

Hold time, stirrer position, and stirring program did not affect yield. All other parameters should be used at the levels specified in the Experimental Procedure. The model predicts that yields approaching $100 \%$ can be obtained by using the best conditions specified above.

Heat of reaction did not cause thermal shock failure of crucibles in this study. Evidence suggested the DOR reaction temperature release can be controlled by stirring rate. This may be beneficial if crucible failure becomes a problem in the future.
There is some evidence that any moisture depresses yield. In two of five experiments where water was absorbed by the plutonium oxide, yields were much lower than the average as predicted by the statistical model for the conditions used. It has been theorized that moisture can cause foaming. No evidence of foaming was observed in these experiments. Considerable effort was put forth to provide careful handling of reagents to ensure minimal moisture absorption. This will be essential. in subsequent DOR work to produce maximum yields.

Foundry specifications for metal purity were satisfied for all impurities analyzed except carbon, calcium, magnesium, and the aluminum, silicon, and gallium combination. Carbon failed to meet foundry specifications in only one of the 32 product buttons and is not considered a problem.

After extensive analyses of impurities, it was determined that iron, chromium, and carbon reports to the product plutonium button from the oxide. Gallium and uranium may report to another product phase; but without better analyses on all the residues, this cannot be conclusively stated. To consider other elements, further analyses of all product phases are required to fully understand and characterize the origination and reporting pattern of each impurity.

If the entire concentration of aluminum, silicon, and gallium had reported to the product, the specification would not have been satisfied. DOR is not a purification process. Attempts to produce foundry-quality metal through DOR or reduction of the quantity of DOR product requiring electrorefining can be successful only if the feed reagents (including plutonium oxide) are relatively free of contaminants.

The results of Phase IIC show that the small-scale studies performed previously correlate very well to production scale. Stirring speed and oxide source were the only parameters that affected the smallscale yields differently than production scale.

Tapered stainless steel back-up cans were effective in making breakouts easier when crucibles failed. 


\section{RECOMMENDATIONS}

It is recommended that future work in DOR continue in the refinement of stirrer design and optimization of calcium excess.

Following is a list of recommended parameters that can be used to attain the highest yields based on the results of this study:

1. Stirrer design: Paddle.

2. Percentage excess calcium: $20 \%$.

3. Salt: Cast calcium chloride.

4. Salt-to-oxide ratio: $4: 1$ (to minimize salt residue).

5. Oxide feed type: Line 16 (continuously precipitated) plutonium oxide calcined at $1000^{\circ} \mathrm{C}$ at least six hours and packaged at $200{ }^{\circ} \mathrm{C}$ in a water-tight vessel.

6. Stirring speed: $600 \mathrm{rpm}$ (ramp to this speed in one to two minutes).

7. Stirring initiation: When the salt becomes molten.

8. Hold time after stirring: 15 minutes.

9. Calcium metal position on loading: Above the oxide.

Emphasis in the future should be placed on acquisition of the purest reagents possible. Any impurities contained in the reagents contaminate the product. Before foundry-quality metal can be produced by the DOR process, aluminum and silicon concentrations in both feed oxides must be reduced. If Line 16 oxide is used, the gallium concentration must also be reduced. The Fisher C-77 calcium chloride salt and the Pfizer calcium metal used had acceptable purities.

The data gathered in this study does not conclusively show that calcium and magnesium contamination of the product can be reduced by varying any of the parameters used. Since these two elements were present in most of the products in quantities considerably above foundry specifications it is recommended that a batch of DOR buttons, produced under conditions similar to Phase IIC, be cast by the foundry to determine their effect on casting yield and quality. Calcium and magnesium concentrations in buttons produced by using 10 or $20 \%$ excess calcium may not be detrimental to the foundry casting process.

The results of this study showed that $10 \%$ excess calcium increased the average concentrations of gallium and nickel. Future work in DOR should verify this result and determine its cause.

Because water decreases yields, it is recommended that reagents be handled to minimize water absorption.

Further work should be done to characterize differences between Line 16 and PSL oxide.

Verification of the results of Phase IIC is recommended. After the stirrer design and excess calcium are refined, a baseline set of runs should be performed using a consistent set of parameters. This would include plutonium oxide batches produced under the same set of conditions. Inconsistent feed may provide inconsistent results.

In future DOR development efforts where large numbers of experiments are required, it is recommended that preliminary screening work be performed on a scale similar to one used in the small-scale studies. Performance on the small scale is similar to production scale, saves time and nuclear material resources, and reduces residues requiring. further processing

\section{REFERENCE}

1. J. L. Long, D. J. Santi, D. C. Fisher, and T. J. Humiston, DOR Demonstration 1. Small Scale Studies, RFP-4128, Rockwell International, Rocky Flats Plant, Golden, CO, April 1987. 


\section{APPENDIX A}

\section{Foundry Specifications for Plutonium Metal}

\begin{tabular}{|c|c|c|c|}
\hline Element & $\begin{array}{c}\text { Maximum } \\
(\mathrm{ppm})\end{array}$ & Element & $\begin{array}{c}\text { Maximum } \\
(\mathrm{ppm})\end{array}$ \\
\hline $\mathrm{Al}$ & $*$ & $\mathrm{Mn}$ & 100 \\
\hline $\mathrm{Am}$ & 200 & $\mathrm{Ni}$ & $* *$ \\
\hline B & 50 & $\mathrm{~Np}$ & 100 \\
\hline $\mathrm{Be}$ & 3 & $\mathrm{~Pb}$ & 100 \\
\hline $\mathrm{C}$ & 200 & $\mathrm{Si}$ & $*$ \\
\hline $\mathrm{Ca}$ & 500 & $\mathrm{Sn}$ & 100 \\
\hline $\mathrm{Cd}$ & 10 & $\mathrm{Ta}$ & 100 \\
\hline $\mathrm{Cr}$ & 100 & Th & 100 \\
\hline $\mathrm{Cu}$ & 100 & $\mathrm{Ti}$ & 100 \\
\hline $\mathrm{Fe}$ & $* *$ & $\mathrm{U}$ & 100 \\
\hline $\mathrm{Ga}$ & $*$ & W & 200 \\
\hline $\mathrm{Mg}$ & 500 & $\mathrm{Zn}$ & 100 \\
\hline
\end{tabular}


RFP-4204

\section{DO NOT MICROFILM THIS PAGE}

